\title{
Pemberdayaan Kader Kesehatan Pos Pelayanan Terpadu (Posyandu) dalam Merawat Bayi Sakit Kuning Di Rumah
}

\author{
Herlina*, Rokhaidah, Indah Permatasari \\ Jurusan Keperawatan Fakultas Ilmu Kesehatan \\ Universitas Pembangunan Nasional (UPN) 'Veteran' Jakarta \\ *E-mail : herlinamail@yahoo.co.id \\ DOI: https://doi.org/10.21107/pangabdhi.v6i2.8160 \\ Naskah diterima 1 Agustus 2020, Revisi 10 Agustus 2020, Terbit 29 Oktober 2020
}

\begin{abstract}
Abstrak
Pada masa pandemik Covid-19 ini pemerintah menghimbau warga untuk meminimalkan pergi ke rumah sakit kecuali keadaan gawat. Bayi sakit kuning merupakan gangguan kesehatan yang umum terjadi pada bayi baru lahir dan bukan merupakan kondisi gawat kecuali bila telah muncul komplikasi. Solusi untuk masalah kesehatan bayi ini adalah memaukan keluarga untuk merawat bayi sakit kuning di rumah. Pemberdayaan masyarakat untuk mendampingi keluarga adalah Kader Posyandu. Kegiatan pengabdian kepada masyarakat ini bertujuan meningkatkan kemampuan Kader Posyandu merawat bayi sakit kuning di rumah dengan benar. Kegiatan ini dilakukan dengan metode penyuluhan pada 35 orang kader yang berasal dari 7 Posyandu di wilayah Kecamatan Baros, Serang, Banten. Media penyuluhan menggunakan booklet dan video tutorial tentang perawatan bayi sakit kuning di rumah. Kegiatan dilaksanakan dalam tiga tahap: 1) Tahap persiapan menghasilkan rencana dan metode kegiatan; 2) Tahap pelaksanaan berupa kegiatan penyuluhan; 3) Tahap paska kegiatan berupa pendampingan melalui aplikasi whatsapp. Hasil kegiatan ini adalah meningkatnya pengetahuan dan kemampuan kader untuk mengidentifikasi: 1) penyebab dan gejala; 2) perawatan dan pemantauan bayi sakit kuning di rumah.
\end{abstract}

Kata Kunci: bayi kuning, kader posyandu, penyuluhan, perawatan di rumah

\begin{abstract}
During the Covid-19 pandemic, the government urged residents to minimize going to the hospital unless there was an emergency. Jaundice is a common health problem in newborns and is not a serious condition unless complications have arisen. The solution to this baby's health problem is to get the family to care for the jaundice at home. Community empowerment to support families is Posyandu cadres. This community service activity aims to improve the ability of Posyandu cadres to properly care for jaundiced babies at home. This activity was carried out by extension methods to 35 cadres from 7 Posyandu in the Baros District, Serang, Banten. Extension media uses booklets and video tutorials on caring jaundice at home. The activity is carried out in three stages: 1) The preparation stage produces plans and activity methods, 2) The implementation stage is in the form of extension activities, 3) The post-activity stage is in the form of assistance through the WhatsApp application. The result of this activity is the increased knowledge and ability of cadres to identify: 1) causes and symptoms, 2) care and monitoring of jaundice at home.
\end{abstract}

Key Words : jaundice, newborn, posyandu cadres, counseling, home care

\section{PENDAHULUAN}

Hasil penelitian pengusul pada tahun 2019 menunjukkan masalah kesehatan yang paling banyak dialami oleh bayi baru lahir atau berusia 0 tahun adalah hiper-bilirubinemia atau dikenal dengan sebutan bayi kuning. Hiper-bilirubinemia terjadi karena meningkatkanya kadar bilirubin dalam darah. Akut hiperbilirubinemia dapat menyebabkan kernikterus yaitu toksisitas otak (Lauer dan Spector, 2011). Deteksi dini terhadap resiko severe hiperbilirubinemia merupakan langkah penting untuk menghindari bilirubin encephalopati ataupun kernikterus (Khairy et al., 2019).

Terapi pijat bayi yang dikombinasikan dengan frekuensi menyusu ASI terbukti efektif memperbaiki kadar bilirubin pada bayi yang mengalami breast milk jaundice (Fei et.al., 2018). Inisiasi menyusui dini (IMD) terbukti mampu menurunkan resiko bayi mengalami hiperbilirubinemia (DeWeese, 2016). Tenaga kesehatan disarankan untuk memberikan dukungan kepada ibu agar tetap melanjutkan ASI 
ekslusif bila bayi mengalami breast milk jaundice (Muchowski, 2014).

Bayi hiperbilirubinemia akan dipulangkan ke rumah setelah kondisi kesehatan membaik. Edukasi keluarga yang akan merawat bayi di rumah efektif bila menggunakan ilustrasi, kalimat yang sederhana, dan pembicaraan aktif dua arah (Dantas et.al, 2016). Keluarga harus mendapatkan pendidikan kesehatan dan paham tenang deteksi dini jaundice serta kemana keluarga harus mencari pertolongan bila menemukan gejala jaundice pada bayinya (Wells et.al, 2013).

Desa Baros memiliki penduduk berusia 0-4 tahun sebanyak 5992 sedangkan tidak ada fasilitas kesehatan berupa rumah sakit (BPS Serang, 2018). Bayi kuning yang tidak mendapatkan perawatan optimal akan mengalami keracunan otak yang dapat berujung pada kematian (Lauer dan Spector, 2011). Sedangkan angka kematian bayi karena sebab yang dapat dicegah belum mencapai target secara nasional yaitu 12 per 1000 kelahiran (BPS, 2016).

Pada masa pandemik covid-19 ini pemerintah menghimbau untuk konsultasi kesehatan melalui layanan jarak jauh dan mempertimbangkan jadwal kunjungan (KEMENKES, 2020). Dengan demikian diharapkan warga dapat menjaga dan merawat kesehatan termasuk kesehatan bayi baru lahir yang beresiko mengalami sakit kuning. Hasil studi pendahuluan pengusul di wilayah Desa Baros menunjukkan ada 35 kader kesehatan Posyandu. Hal ini dapat dimanfaatkan untuk memberdayakan warga dalam mencegah terjadinya bayi kuning maupun merawat bayi kuning dengan benar. Bila warga telah mampu merawat bayi dengan benar diharapkan dapat menekan angka kematian bayi karena sebab yang dapat dicegah sehingga membantu pemerintah mencapai target menekan angka kematian bayi karena sebab yang dapat dicegah kurang dari 12 per 1000 kelahiran pada tahun 2030.

Berdasarkan uraian di atas sangat penting memberdayakan kader kesehatan posyandu untuk dapat membantu memandirikan keluarga merawat bayi sakit kuning dengan benar. Kegiatan ini diharapkan mampu mengoptimalkan peran keluarga dalam merawat bayi sakit kuning sehingga cepat sembuh dan tidak terjadi komplikasi meskipun di rawat di rumah.

\section{METODE}

Kegiatan pengabdian ini dilaksanakan sebagai perwujudan dari tri dharma perguruan tinggi. Kegiatan bertujuan memberdayakan kader posyandu untuk mampu mendampingi warga merawat bayi sakit kuning di rumah. Sasaran kegiatan ini adalah kader kesehatan Posyandu di wilayah Kecamatan Baros, Kabupaten Serang, Banten. Jumlah kader yang terlibat adalah 35 orang kader yang berasal dari 7 Posyandu.

Kegiatan dirancang dalam tiga tahap yaitu tahap perencanaan, tahap pelaksanaan dan tahap paska pelaksanaan. Tahap pelaksanaan terdiri dari kegiatan survey ke lokasi, kontrak kesediaan mitra kegiatan yaitu posyandu, dan penyusunan rancangan kegiatan. Tahap pelaksanaan kegiatan semula direncanakan untuk penyuluhan dan praktek, tetapi karena kebijakan pembatasan sosial berskala besar (PSBB) maka kegiatan secara laring ini diganti dengan kegiatan daring. Kegiatan daring mencakup penyuluhan perawatan bayi sakit kuning dengan media video, booklet cetak dan e-booklet. Diskusi dan Tanya jawab dilakukan melalui aplikasi whatsapp.

Materi penyuluhan dan diskusi mencakup: 1) Penyebab dan gejala, 2) Perawatan dan Pemantauan kondisi bayi kuning. Pemahaman kader terhadap materi penyuluhan diukur dua kali yatu sebelum penyuluhan dan setelah penyuluhan. Kuisener terdiri dari 10 pernyataan yang semuanya benar sehingga skor jawaban berkisar antara 0-10. Tahap ketiga adalah tahap paska edukasi. Kegiatan tahap ini adalah pendampingan melalui aplikasi whatsapp baik chat maupun videocall whatsapp.

Target luaran pada serangkaian kegiatan ini adalah peningkatan pengetahuan kader, pemanfaatan media booklet dan video untuk edukasi perawatan bayi kuning di rumah.

\section{HASIL DAN PEMBAHASAN}

Kegiatan dilaksanakan secara laring pada bulan Juli 2020. Kegiatan diawali dengan diskusi tentang metode yang mampu laksana di wilayah Baros terkait dengan kebijakan PSBB. Didapatkan hasil bahwa penyuluhan dilakukan secara daring. FGD dilanjutkan dengan metode penyuluhan yang mampu laksana secara daring. Kegiatan daring ini terkendala dengan jaringan internet yang tidak stabil. Untuk mengatasi kendala jaringan maka dibuatlah media yang dapat diakses dengan mudah oleh para kader 
yaitu video dan e-booklet seperti terlihat pada Gambar 1.

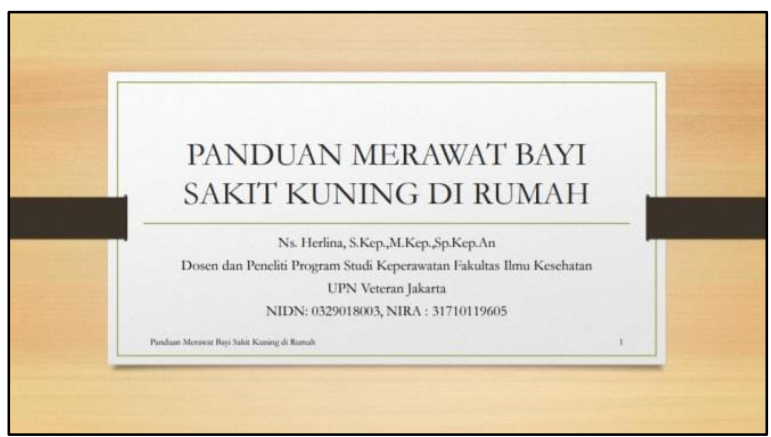

Gambar 1. Booklet Perawatan Bayi Sakit Kuning di Rumah

Peningkatan pengetahuan diukur dengan menggunakan kuisener cetak karena kader tidak dapat mengakses kuisener pada platform Google Form. Booklet dan kuisener cetak dikirimkan kepada kader melalui ekspedisi ke Posyandu di wilayah Kecamatan Baros dan dikoordinir oleh satu orang kader koordinator seperti terlihat pada Gambar 2.

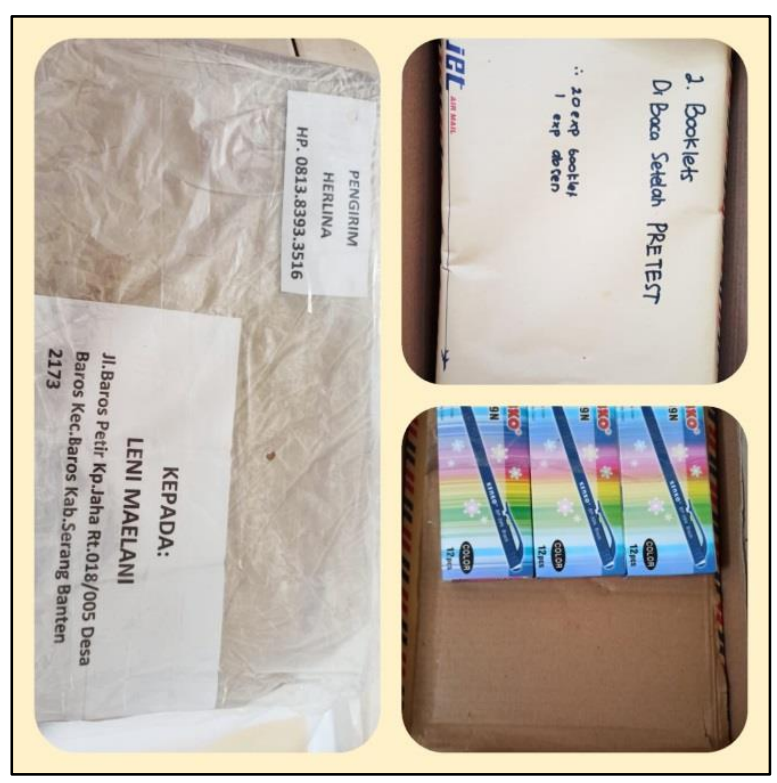

Gambar 2. Paket Penyuluhan yang Dikirimkan Melalui Ekpedisi

Video penyuluhan berdurasi 4 menit menjelaskan isi dari booklet seperti tampak pada gambar 3. Video ini dikirimkan melalui aplikasi whatsapp. Semula penyuluhan akan dilakukan dengan penyuluhan online tetapi jaringan tidak stabil di daerah Baros sehingga dkhawatirkan penyuluhan tidak optimal. Diskusi dengan kader menghasilkan kesepakatan media yang dapat diterima dengan baik adalah video. Agar materi dapat diterima dengan optimal maka materi penyuluhan disampaikan dalam bentuk video.

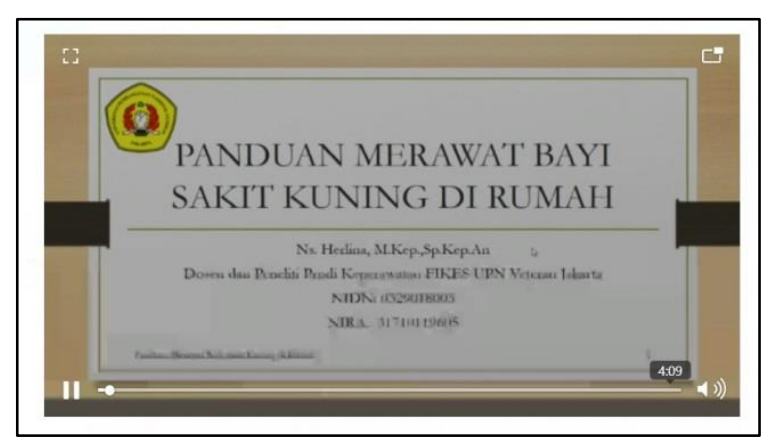

Gambar 3. Video Penyuluhan Berdurasi empat

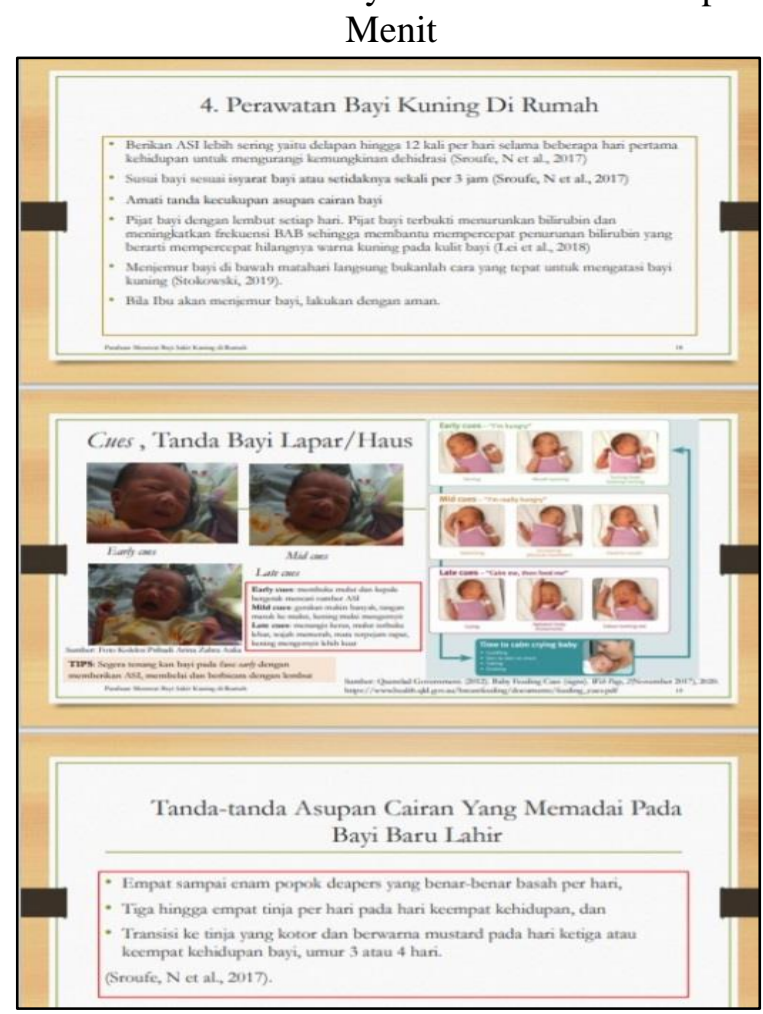

Gambar 4. Materi Penyuluhan Tentang ASI

Perbaikan pengetahuan kader tentang perawatan bayi kuning terlihat pada semua materi. Pengetahuan kader tentang peranan air susu ibu (ASI) dalam mengatasi penyakit bayi kuning menjadi pengetahuan baru bagi para kader. Materi tentang ASI ini terlihat pada gambar. Sebelum penyuluhan tidak semua kader mengetahui peranan ASI. Setelah penyuluhan semua kader mengetahui peranan ASI, frekuensi pemberian ASI yang tepat, dan memantau kecukupan cairan bayi dengan benar.

Pengetahuan kader juga tampak meningkat pada materi mengenal tanda bahaya bayi sakit kuning. Sebelum penyuluhan tidak semua kader mengetahui tanda bahaya bayi kuning dan tidak mengetahui tindakan apa yang perlu dilakuan. 
Materi penyuluhan tanda bahaya bayi kuning tampak seperti pada Gambar 5. Setelah penyuluhan semua kader mengetahui tanda bahaya dan tindakan yang benar.

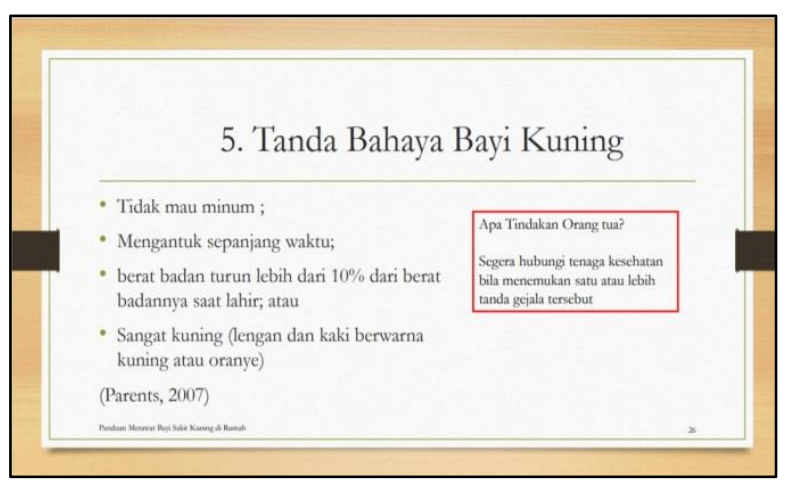

Gambar 5. Materi Tanda Bahaya Bayi Sakit

Kuning dan Tindakan yang Tepat.

Kader Posyandu selama ini menganggap bahwa menjemur bayi adalah tindakan yang paling tepat untuk menyembuhkan bayi sakit kuning. Anggapan ini tidak tepat karena menjemur bayi di bawah sinar matahari langsung berbahaya bagi bayi. Bahaya ini muncul disebabkan oleh kulit bayi yang sangat tipis dan melanin yang masih sedikit tidak mampu menahan panas sinar matahari dengan baik sehingga beresiko terjadi sunburn dan potensial gangguan kulit dikemudian hari. Selain itu kulit bayi yang tipis belum mampu menahan penguapan air tubuh dengan baik, sehingga menjemur bayi dapat menyebabkan bayi kehilangan cairan serta dehidrasi. Materi tentang menjemur bayi yang benar diberikan pada tahap penyuluhan seperti tampak pada Gambar 6 .

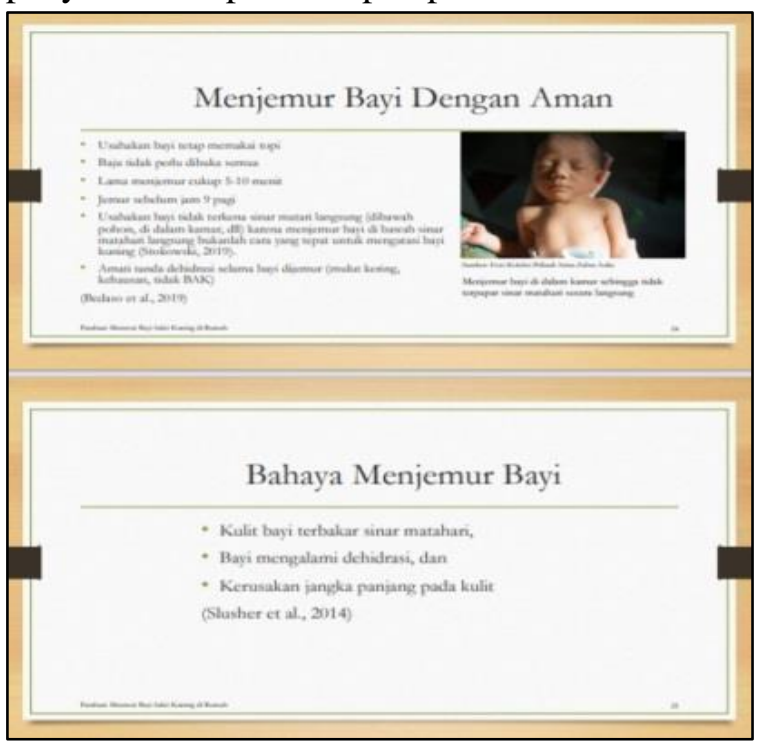

Gambar 6. Materi Menjemur Bayi
Kader posyandu mendapatkan instrument untuk mengukur penyerapan materi oleh warga ketika melakukan edukasi. Instrument ini penting untuk mengukur sukses tidaknya edukasi. Dengan instumen ini pula kader dapat mengetahui materi apa yang belum dipahami dan perlu dijelaskan lebih mendalam.

\section{KESIMPULAN}

Dari serangkaian kegiatan program kemitraan masyarakat ini disimpulkan bahwa kegiatan ini telah tepat sasaran dan tujuan pemberdayaan kader telah tercapai. Setelah menyelesaikan semua modul penyuluhan, ada peningkatan pengetahuan dan perbaikan opini kader tentang perawatan bayi sakit kuning di rumah. Pada masa pandemik Covid-19 ini aktifitas penyuluhan berbeda dengan masa sebelumnya. Tantangan untuk dapat memberdayakan kader adalah penyampaian materi penyuluhan dan pendampingan harus dilakukan jarak jauh karena adanya kebijakan PSBB.

Namun demikian tetap diharapkan hasil kegiatan jarak jauh ini sama dengan hasil penyuluhan pendampingan yang dilaksanakan secara langsung. Pemanfaatan media sosial dan aplikasi sangat membantu dalam pencapaian tujuan kegiatan, namun demikian jaringan internet yang tidak stabil menjadi kendala pada pelaksanaan kegiatan sehingga diperlukan alternatif media yang dapat menjangkau semua kader.

\section{UCAPAN TERIMA KASIH}

Tim Pengabdi mengucapkan terimakasih kepada UPN Veteran Jakarta yang telah memberikan dukungan pendanaan untuk pelaksanaan kegiatan pengabdian kepada masyarakat ini.

\section{DAFTAR PUSTAKA}

BPS. 2016. Potret Awal Tujuan Pembangunan Berkelanjutan (Sustainable Development Goals).https://www.bps.go.id/publication/d ownload.

BPS Serang. (2018). Kecamatan Baros dalam angka 2018. BPS Serang. https://serangkab.bps.go.id/publication/dow nload. 
Dantas, A., Castro, N., Cardoso, M., Guedes, N., Lopes, M., \& Araújo, N. 2016. Educational Booklet on Neonatal Jaundice: An Approach For Caregivers. International Archives of Medicine. https://doi.org/10.3823/2184

DeWeese, A. 2016. Reducing Neonatal Hyperbilirubinemia With the Baby-Friendly Initiative. Journal of Obstetric, Gynecologic \& Neonatal Nursing. Vol 45 (3). S50. https://doi.org/10.1016/j.jogn.2016.03.125

Fei, Y., Wang, C., \& Du, Y. 2018. Causes of Breast-Feeding Jaundice And Clinical Efficacy Analysis of Nursing Intervention. International Journal of Clinical and Experimental Medicine. Vol 11 (12). 13645-13650 pp.

KEMENKES. (2020). Gugus tugas percepatan penanganan covid-19 1. Gugus Tugas Percepatan Penanganan Covid-19. 1-39 pp.
Khairy, M. A., Abuelhamd, W. A., Elhawary, I. M., \& Mahmoud Nabayel, A. S. (2019). Early Predictors of Neonatal Hyperbilirubinemia In Full Term Newborn. Pediatrics and Neonatology. 60 (3). 285290

pp. https://doi.org/10.1016/j.pedneo.2018.07.00 5

Lauer, B. J., \& Spector, N. D. 2011. HyperBilirubinemia In The Newborn. Pediatrics in Review. Vol 32 (8). 341-349 pp. https://doi.org/10.1542/pir.32-8-34.

Muchowski, K. E. 2014. Evaluation And Treatment of Neonatal Hyperbilirubinemia. American Family Physician. Vol 89 (11). 873-878 pp.

Wells, C., Ahmed, A., \& Musser, A. 2013. Strategies for neonatal hyperbilirubinemia: A literature review. MCN The American Journal of Maternal/Child Nursing. Vol 38 (6) 377-382

pp. https://doi.org/10.1097/NMC.0b013e3182a $\underline{1 \mathrm{fb} 7 \mathrm{a}}$. 
74 Jurnal Pangabdhi 